\title{
Ethene and butene oligomerization over isostructural H-SAPO-5 and H-SSZ-24: Kinetics and mechanism
}

\author{
Christian Ahoba-Sam, Marius Westgård Erichsen , Unni Olsbye * \\ SMN Centre for Materials Science and Nanotechnology, Department of Chemistry, University of Oslo, N-0315 Oslo, Norway. ${ }^{a}$ Current address: Matriks AS, \\ Gaustadallèen 21, 0349 Oslo, Norway
}

\section{A R T I C L E I N F O}

\section{Article history:}

Received 17 June 2019

Accepted 20 June 2019

Published 5 November 2019

\section{Keywords:}

Ethene oligomerization

Butene oligomerization

Kinetics

Zeolite

Acid strength

H-SSZ-24
H-SAPO-5

\begin{abstract}
A B S T R A C T
Brønsted-acidic zeolite and zeotype materials are potential catalysts for the conversion of ethene to higher alkenes. In this study, two materials with AFI structure but different acid strength, H-SAPO-5 and H-SSZ-24, were subject to studies of ethene, cis-2-butene and ethene-butene mixture conversion under conditions where $\mathrm{C}_{3}-\mathrm{C}_{5}$ alkene formation is thermodynamically favoured over higher hydrocarbons (673-823 K, $1 \mathrm{~atm})$. Ethene and cis-2-butene partial pressures were varied in the range 9-60 and $0.9-8.1 \mathrm{kPa}$, respectively, and contact times were varied in the range 3.78-756 and 0.573-76.4 s. $\mu \mathrm{mol} \mathrm{H}+/ \mathrm{cm}^{3}$ over H-SAPO-5 and H-SSZ-24, respectively. Less than $1 \%$ conversion of ethene and less than $10 \%$ conversion of butene was obtained in the range of conditions used for elucidation of rate parameters.

The ethene conversion rates were more than an order of magnitude higher over the more acidic H-SSZ-24 than over H-SAPO-5 (6.5 vs. $0.3 \mathrm{mmol} / \mathrm{mol} \mathrm{H}^{+} . \mathrm{s}$ at $748 \mathrm{~K}, P_{\text {ethene }}=33 \mathrm{kPa}$ ), with corresponding lower reaction order in ethene (1.5 vs. 2.0 at $673 \mathrm{~K}$ ) and lower apparent activation energy (52 vs. $80 \mathrm{~kJ} / \mathrm{mol}$ at 698-823 K). Propene selectivity was substantially higher over H-SSZ-24 than over H-SAPO-5 (68\% vs. $36 \%$ at $0.5 \%$ ethene conversion). A similar difference in apparent reaction rates was observed for cis-2-butene conversion over the two catalysts, and for co-feeds of ethene and cis-2-butene. However, the cis-2-butene conversion to $\mathrm{C}_{3}-\mathrm{C}_{5}$ alkenes was found to be severely influenced by thermodynamic limitations, impeding a detailed kinetic analysis, and leading predominantly to isobutene formation at the highest temperatures.
\end{abstract}

(C) 2019, Dalian Institute of Chemical Physics, Chinese Academy of Sciences. Published by Elsevier B.V. All rights reserved.

\section{Introduction}

propene; but also butenes and butadienes.

Oligomerization of ethene to butene is a commercial process

Light olefins are important raw materials for the production of commodity products and fuels [1,2]. In recent years, oil reserve depletion as well as abundant shale gas reserves with up to $10 \%$ ethane content has led to refurbishment of naphta crackers into ethane crackers. Naphta crackers yield a mixture of ethene, propene, butenes and butadienes, but ethane crackers yield almost exclusively ethene [2]. Another, more environmentally benign source of ethene is bioethanol [3]. Together, these recent feedstock changes have spurred the interest for converting ethene into other light olefins and dienes, primarily that employs homogeneous Ni complex catalysts, yielding high 1-butene selectivity. Propene may be obtained by subsequent conversion of 1-butene to 2-butene, followed by a metathesis reaction. In recent years, heterogenisation of the Ni-complex catalysts was extensively studied. Typically, mono-Ni precursor complexes were grafted onto nanoporous materials such as zeolites, mesoporous silica-alumina or metal-organic frameworks. The product distribution is similar to that observed over homogeneous Ni complexes, with a high abundance of linear butenes [3-5].

\footnotetext{
* Corresponding author. Tel: +4722855456; E-mail: unni.olsbye@kjemi.uio.no DOI: S1872-2067(19)63426-1 | http://www.sciencedirect.com/science/journal/18722067 | Chin. J. Catal., Vol. 40, No. 11, November 2019
} 
Brønsted acidic zeolites and zeotypes represent another class of potential ethene oligomerization catalysts [6]. Over these materials, the reaction proceeds via carbocationic intermediates, as demonstrated by in-situ FTIR studies [7,8]. High propene selectivity $(40 \%-80 \%)$ is commonly reported at 673-823 K [5,6,8-10]. However, ethene can only form primary carbocations that are inherently unstable [11]. For this reason, dimerization of ethene is slow compared to reactions of longer chain alkenes that form more stable secondary and tertiary carbocations upon protonation. The difference is illustrated by a recent study where Zhou et al. [12] reported that at $723 \mathrm{~K}$ and similar space velocity, conversion of butene and propene over H-ZSM-5 was more than 9 times faster than ethene conversion. Hence, larger product variety is observed over H-based catalysts than over Ni-based catalysts $[3,10]$. In zeolites and zeotypes, product selectivity is strongly influenced by the size and connectivity of micropores; by restricting the space available for reaction, and by stabilisation of transition states through Coulombic interactions with the surrounding lattice (shape selectivity) [13-17]. Recently, Sarazen et al. [15,16] performed a systematic study of the influence of zeolite topology by converting $\mathrm{C}_{2}-\mathrm{C}_{4}$ alkenes over zeolites with TON, MFI, MOR, BEA, FAU topology, and furthermore, the influence of acid strength by incorporating $\mathrm{Al}, \mathrm{Ga}, \mathrm{Fe}$ or $\mathrm{B}$ as heteroatom in the MFI structure. The study was performed at $473-533 \mathrm{~K}$ and $2-400$ $\mathrm{kPa}$ alkene, and showed that confinement has beneficial effect on $\mathrm{C}-\mathrm{C}$ bond formation. On the incorporation of heteroatoms, they observed that the dimerization rate increased with decreasing deprotonation energy as the more stable conjugate anions of the solid acids stabilized carbocation transition states.

Two mechanisms have been proposed for ethene oligomerization; the oligomerization-cracking scheme and the aromatic scheme (Scheme 1). The aromatic scheme was proposed based on studies of ethene oligomerization over H-SSZ-13 [18], a catalyst with cavity-window structure that favours aromatics formation.

Most studies of the ethene oligomerization reaction refer experimental findings to the oligomerisation-cracking mechanism. During reactions of $n$-butenes, propene, iso-butene and pentene are commonly observed [19-22], as indicated in Scheme 1. Propene can be formed from $\beta$-scission of ethene oligomers ranging from hexene to higher hydrocarbons $[9,23]$.
While the formation of propene and pentene is widely accepted to occur by butene dimerization and cracking, there is no consensus on the formation of iso-butene. Mooiweer et al. [19] and Guisnet et al. [21] based on kinetic measurement and modelling over H-FER suggested dimerization, isomerization and cracking leading to iso-butene formation; usually referred to as the bimolecular pathway. Direct isomerization of $n$-butene was ruled out based on the unstable primary iso-butyl carbenium ion intermediate which was suspected to be involved.

However, other reports have suggested a different pathway for iso-butene formation. Houžvička et al. [22,24] suggested a direct isomerization of $n$-butene to iso-butene usually referred to as the monomolecular pathway, over H-FER. The conclusion was based on experiments using various octane reactants. The selectivity to propene and pentenes was higher than the selectivity to iso-butene when different dimers of butene were the reactants. On the contrary, selectivity to iso-butene was higher than the selectivity to propene and pentenes when $n$-butene was the reactant, leading to their conclusion that, $n$-butene directly isomerizes to iso-butene.

Isotopic labelling experiments have been reported with the aim to distinguish between these mechanisms. Meriaudeau et al. [25] reported that ${ }^{13} \mathrm{C}$ labelled $n$-butene $\left({ }^{13} \mathrm{C}-12 \mathrm{C}_{3} \mathrm{H}_{8}\right)$ over fresh $\mathrm{H}-\mathrm{FER}$ at $673 \mathrm{~K}$ showed only single labelled ${ }^{13} \mathrm{C}$ iso-butene, in support of the monomolecular pathway. Similar experiment by Čejka et al. [26] over fresh H-FER at $620 \mathrm{~K}$ reported that while about $30 \%$ of the iso-butene (out of $50.6 \%$ overall iso-butene selectivity) showed either double or no labelling as a result of bimolecular pathway, the remaining iso-butene formed were single labelled, implying a possible monomolecular pathway formation as well. ${ }^{13} \mathrm{C}$ NMR measurement showed that the position of the ${ }^{13} \mathrm{C}$ atom in the iso-butene was evenly distributed as $\mathrm{CH}_{3}: \mathrm{CH}_{2}: \mathrm{C}=1.5: 1: 1$, which is suggestive of a possible methyl cyclo-propyl carbocation intermediate during the monomolecular pathway.

Seo et al. [27] reported that structure of the zeolite play an important role in $n$-butene skeletal isomerization by comparing 10- and 12-ring zeolites at $723 \mathrm{~K}$. H-FER and H-CLI (H-HEU) with 10-rings and intersecting 8-rings showed higher iso-butene selectivity compared with H-MFI (10-ring) and H-BEA (12-ring) which favoured higher $\mathrm{C}_{3}+\mathrm{C}_{5}=$ formation. Houžvička et al. [28] compared shape selectivity of various
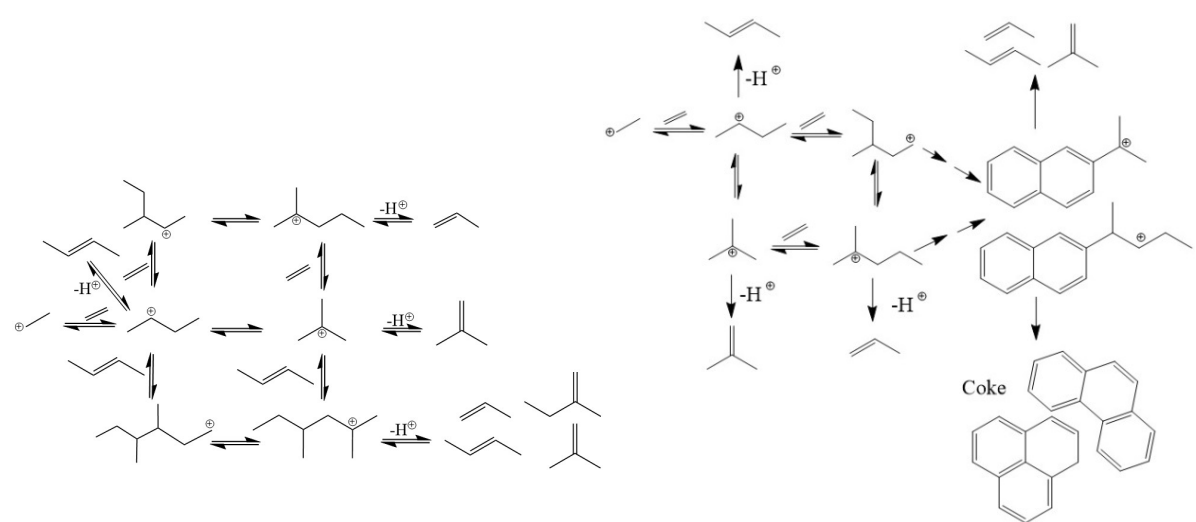

Scheme 1. Ethene oligomerization mechanisms suggested in literature. The oligomerisation-cracking mechanism (left) adapted from [6,9] and the aromatic pool mechanism (right) adapted from $[6,10,18]$. 
pore sizes for $n$-butene skeletal isomerization and concluded that 10-membered rings were most suitable for skeletal isomerization.

The aim of the current study was to elucidate the effect of acid strength on the ethene oligomerization reaction under conditions where thermodynamics favour formation of $\mathrm{C}_{3}-\mathrm{C}_{5}$ products; i.e. at $623-823 \mathrm{~K}$. To this aim, we selected a zeolite, H-SSZ-24, and a zeotype, H-SAPO-5, material. Both materials belong to the family of materials with AFI topology, but H-SSZ-24 has substantially higher acid strength than H-SAPO-5 $[29,30]$. The AFI topology has uniform, straight 1-dimensional 12-ring pores with $0.83 \mathrm{~nm}$ pore size. This structure was selected for several reasons: First, the pore size is wide enough to allow diffusion of aromatic products (suggested to be intermediates of reaction in zeolites with restricted pore windows, see Scheme 1) out of the pores and into the gas effluent. Second, the AFI structure has only one T-site, which means that all Brønsted acid sites have the same lattice environment, and third; the straight, 1-dimensional pores offer the same confinement to reacting molecules throughout the catalyst. Provided the Brønsted acid sites are situated sufficiently far apart to avoid interaction between them, this means that differences observed between H-SSZ-24 and H-SAPO-5 as ethene oligomerization catalyst could be ascribed to the difference in their acid strength. To the best of our knowledge, no previous study has reported the effect of acid strength on ethene oligomerization in this temperature range. Furthermore, since most prior studies were conducted using medium pore $(10$ MR) molecular sieves, our study could yield information on the influence of pore size/dimensionality on the title reaction. The kinetic study was conducted under differential conditions, using ethene, cis-2-butene and mixtures thereof as feed, with partial pressure variation in the range $0.9-60 \mathrm{kPa}$.

\section{Experimental}

\subsection{Catalyst preparation and characterization}

The AFI samples used, H-SAPO-5 and H-SSZ-24 have been hydrothermally synthesized and characterized in the same way as was reported elsewhere $[29,30]$. Both samples were characterized with SEM, N2 adsorption and FT-IR. FEI Quanta 200 FEG-ESEM was used to determine particle size as well as the elemental composition of the samples. The surface area was measured using BEL BELSORP-mini II instrument at $77 \mathrm{~K} .50$ mg samples were preheated under vacuum at $353 \mathrm{~K}$ for $1 \mathrm{~h}$ and $573 \mathrm{~K}$ for $4 \mathrm{~h}$ to remove moisture and any other adsorbate before adsorption measurement. BET equation was used to estimate the specific surface area. A CO-adsorption FT-IR was done to distinguish the acid strength of the two catalysts using a Vertex 80 instrument with MCT (mercury cadmium telluride) detector in transmission mode. The samples were prepared by grinding gently to ensure homogeneity and pressed into a self-supporting disk. The samples were pre-treated under vacuum at 423, 573 and $723 \mathrm{~K}$ for $1 \mathrm{~h}$ each to remove any moisture and other adsorbate.

\subsection{Catalytic test}

All catalytic tests were done using a fixed bed glass reactor with 4 or $8 \mathrm{~mm}$ inner bed diameter depending on the amount of catalyst used. The powdery catalysts were pressed, gently crushed and sieved into pellets between 250 and $420 \mu \mathrm{m}$. The catalyst pellets were calcined in $\mathrm{O}_{2}$ at $823 \mathrm{~K}$ for $1 \mathrm{~h}$ on stream to get rid of any moisture and organic matter before cooling to the reaction temperature for testing. Ethene (99.5\% purity), 9\% cis-2-butene (99\% purity) in Ar and 10\% Ne in He regulated by mass-flow controllers were fed to the reactor via a 125 series nitrogen-piloted four-way valve from Humphrey. A thermocouple was placed in the reactor just on top of the bed to monitor the reaction temperature. The reactor was placed in an oven which was well insulated to ensure stable internal temperature. Blank tests (without catalyst) of ethene at temperatures from 323 to $823 \mathrm{~K}$ showed no detection of other hydrocarbons by the gas chromatography (GC). Blank test of cis-2-butene however, showed up to $5 \%$ 1-butene and trans-2-butene at $823 \mathrm{~K}$; representative of the rapid interconversion between those three compounds (see below). Parameters such as contact time, pressure and temperature were varied.

The reactor effluent was measured after 2 min on stream to ensure constant pressure of reactant in the reactor as well as constant peak area value in the GC [31]. At each specific reaction condition, five measurements were made to ensure precision. All effluent were analysed with a four column Agilent 3000 micro GC each equipped with thermal conductivity detector (TCD) using He as carrier gas. The effluents were analysed based on $\mathrm{C} \%$, using the formulas below:

$$
\begin{aligned}
& \text { Conversion }(\%)=\frac{\text { Total C } \% \text { of products }}{\text { Total C } \% \text { of effluent }} \times 100 \% \\
& \text { Selectivity of } J(\%)=\frac{C \% \text { of product } J}{\text { Total C } \% \text { of products }} \times 100 \% \\
& \text { Yield of } J(\%)=\frac{\text { Conversion } \% \times \text { Selectity of } J \%}{100} \\
& \text { Rate of } J\left(\frac{\mathrm{mol}}{\mathrm{mol} \mathrm{H}^{+} . \mathrm{s}}\right)=\frac{\text { Yield of } J \times \text { flow rate }\left(\frac{\mathrm{mol}}{\mathrm{s}}\right)}{\text { moles of acid site }\left(\mathrm{mol} \mathrm{H}^{+}\right)} \\
& \text {Contact time (s. } \left.\frac{\mathrm{mmol} \mathrm{H}^{+}}{\mathrm{cm}^{3}}\right)=\frac{\text { number of moles of acid site }\left(\mathrm{mmol} \mathrm{H}^{+}\right)}{\text {total gas flow }\left(\frac{\mathrm{cm}^{3}}{\mathrm{~s}}\right)} \\
& \text { Mass balance }=\frac{\text { total C } \%(\text { effluent }) \times \% N e(\text { feed })}{\text { total C } \%(\text { feed }) \times \% N e(\text { effluent })}
\end{aligned}
$$

In Section 3, the reported reaction rates and conversions versus temperature, partial pressure and contact time are normalized to correct for deactivation. The normalization procedure is described in SI, Section S2. On the other hand, all conversion-selectivity correlations are reported using raw data, without normalisation.

Apparent activation energies were calculated from logarithm of the observed reaction rates (per active site) versus the reciprocal of reaction temperature. The implicit assumption of constant reactant concentration was supported by the low conversion levels obtained $(<1 \%$ for ethane, $<10 \%$ for $n$-butene, vide infra). Similarly, logarithmic plots of observed rate versus ethene partial pressure were used to estimate the 
Table 1

Summary of characterization data for H-SAPO-5 and H-SSZ-24 samples.

\begin{tabular}{lccccc}
\hline Sample & $\begin{array}{c}\text { Crystal } \\
\text { size } \\
(\mu \mathrm{m})\end{array}$ & $\begin{array}{c}\text { BET surface } \\
\text { area } \\
\left(\mathrm{m}^{2} \mathrm{~g}^{-1}\right)\end{array}$ & $\begin{array}{c}\text { Theoretical acid } \\
\text { site density (mmol } \\
\left.\mathrm{H}^{+} / \mathrm{g} \text { catalyst }\right)^{*}\end{array}$ & $\begin{array}{c}v(\mathrm{OH}) \\
\text { shift }\end{array}$ & $\begin{array}{c}v(\mathrm{CO}) \\
\text { shift }\end{array}$ \\
\hline H-SAPO-5 & $\sim 2$ & 338 & 0.126 & -260 & +31 \\
H-SSZ-24 & $\sim 0.2$ & 233 & 0.191 & -318 & +33 \\
\hline
\end{tabular}

* Determined by SEM/EDX.

apparent reaction orders.

Thermodynamic analysis for inter-conversion was done by calculating the equilibrium constant, $\mathrm{K}$ using standard Gibbs free energy values obtained from NIST database [32] and Kilpatrick et al. [33]. K was compared with the quotient value, $Q=$ $\left(\prod_{j=1}^{n} P_{j}^{b} / \prod_{i=1}^{m} P_{i}^{a}\right)$, where $P_{\mathrm{i}}$ and $P_{\mathrm{j}}$ are partial pressures of reactants and products, respectively, and a,b are stoichiometric reaction constants. $Q$ was calculated based on the molar yield fraction of reactants and main products in the reactor effluent.

\section{Results and discussion}

\subsection{Characterization}

The characterization data are summarized in Table 1 (details in Figs. S1 and S2). Analysis with the SEM confirmed hexagonal structure of the H-SAPO-5 with about $2 \mu \mathrm{m}$ diameter. H-SSZ-24 formed much smaller crystals of about $0.2 \mu \mathrm{m}$ size and stacked together to form aggregates of about 1 to $2 \mu \mathrm{m}$ size. The BET surface areas of the H-SAPO-5 and H-SSZ-24 samples were estimated to be 338 and $233 \mathrm{~m}^{2} \mathrm{~g}^{-1}$, respectively. Elemental analysis of the sample with EDS (Energy Dispersive Spectroscopy) of SEM showed (Al+P)/Si of 85 for H-SAPO-5 and $\mathrm{Si} / \mathrm{Al}$ of 55 for H-SSZ-24. These ratios correspond to a theoretical acid site concentration of 0.126 and $0.191 \mathrm{mmol} \mathrm{H}^{+} \mathrm{g}^{-1}$ catalyst for H-SAPO-5 and H-SSZ-24 respectively, implying that the acid density ratio of $\mathrm{H}-\mathrm{SSZ}-24 / \mathrm{H}-\mathrm{SAPO}-5=1.5$. Previous investigations of propene oligomerization [34] suggested that, the reaction mechanisms were only affected by acid site density when the $\mathrm{Si} / \mathrm{Al}$ ratios were less than 40 , corresponding to acid site concentration of $0.265 \mathrm{mmol} \mathrm{H}^{+} \mathrm{g}^{-1}$. Lower acid site concentration suppresses side reactions such as hydrogen transfer and dehydrogenation-aromatization [9]. Hence, the difference

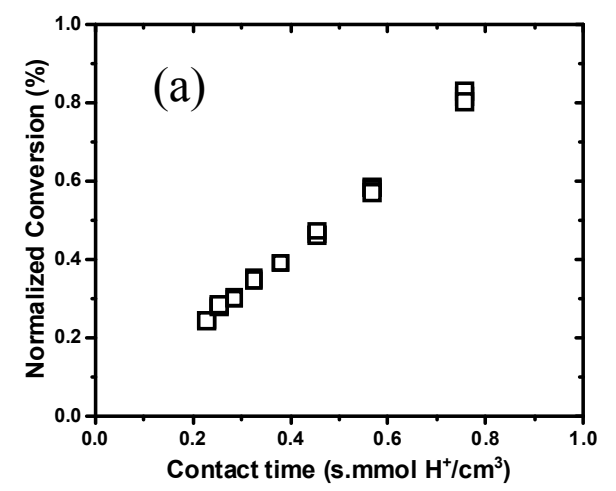

in acid site density in our two samples is not expected to significantly influence reaction mechanism, as the distance between nearby sites is wider.

The FTIR of $\mathrm{CO}$ adsorption showed that the maximum $v(\mathrm{OH})$ shift in the H-SAPO-5 sample was -260 and $-18 \mathrm{~cm}^{-1}$ in $\mathrm{H}-\mathrm{SSZ}-24$ sample. Also, in the CO region, the $\Delta v(\mathrm{CO})$ were +31 and $+33 \mathrm{~cm}^{-1}$ in the H-SAPO- 5 and H-SSZ-24 samples, respectively. By definition, the stronger the acid, the easier its protons interact due to weaker $\mathrm{O}-\mathrm{H}$ bond and larger band shifting is expected when CO (base) adsorbs [35]. Hence the $v(\mathrm{OH})$ shifting indicated that H-SSZ-24 has stronger Brønsted acid sites compared to the strength of H-SAPO-5 acid sites. Further characterisation data is available as supporting information (Fig. S2).

\subsection{Ethene oligomerisation}

Ethene oligomerization conversion obtained over H-SAPO-5 and H-SSZ-24 with increasing contact time at $748 \mathrm{~K}$ are shown in Figs. 1(a) and (b) respectively. Catalyst conversion increased linearly with increasing contact time over both catalysts, indicating that the observed ethene conversion rate was not influenced by products in this conversion range $(0 \%-1 \%)$. Furthermore, conversion was far from thermodynamic equilibrium (See Supporting Information, Fig. S3). Hence, kinetic information obtained for the title reaction over these two catalysts reflects their pristine interaction with ethene. The influence of ethene partial pressure (10-60 $\mathrm{kPa}$ ) and reaction temperature (673-823 K) on ethene conversion rates are shown in Figs. 2 and 3 , respectively, for both catalysts. A larger set of rate parameters is summarized in Table 2 .

A comparison between the two catalysts shows that the reaction order in ethene is significantly higher over H-SAPO-5 than over H-SSZ-24 (2.0 vs 1.5 at $673 \mathrm{~K}$ and 2.1 vs 1.9 at $748 \mathrm{~K}$; Table 2). Furthermore, the ethene conversion rate is more than an order of magnitude higher over the catalyst with higher acid strength, $\mathrm{H}-\mathrm{SSZ}-24(0.3$ versus $6.5 \mathrm{mmol} /(\mathrm{mol} \mathrm{H}+. \mathrm{s})$ at $748 \mathrm{~K}$, $33 \mathrm{kPa}$ ethene; Fig. 2). The observed influence of acid strength is not surprising, when taking into account that proton transfer to ethene will create an unstable primary carbocation, before reaction with a second incoming ethene molecule; possibly preceded by ethoxy formation [17]. Focusing next on the ap-

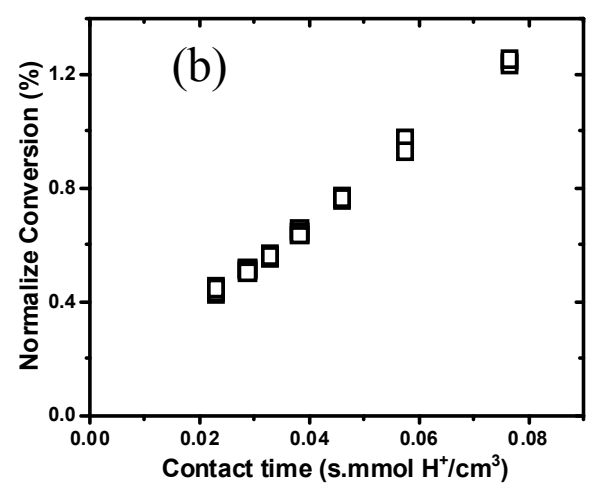

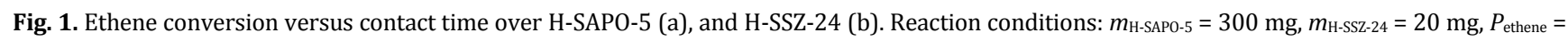
$33 \mathrm{kPa}, T=748 \mathrm{~K}$. 


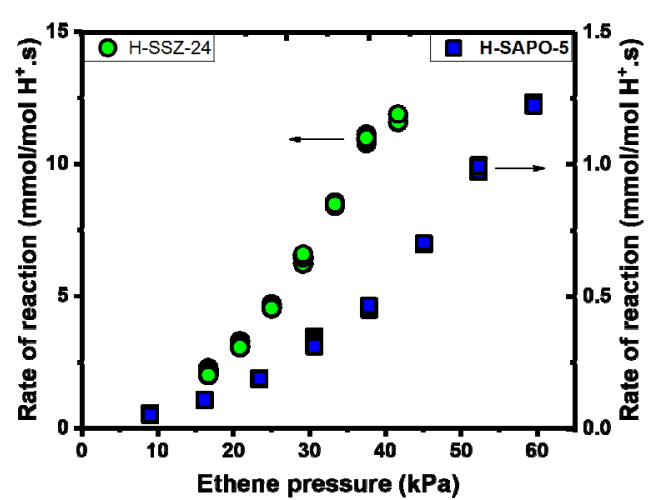

Fig. 2. Reaction rate versus ethene pressure. Reaction conditions: $\mathrm{CT}_{\mathrm{H}-\mathrm{SAPO}-5}=0.1 \mathrm{~s} . \mathrm{mmol} \mathrm{H}^{+} \mathrm{cm}^{-3}, \mathrm{CT}_{\mathrm{H}-\mathrm{SSZ}-24}=0.01 \mathrm{~s} . \mathrm{mmol} \mathrm{H}^{+} \mathrm{cm}^{-3}, T=748$ $\mathrm{K}$, ethene conversion $<1 \%$.

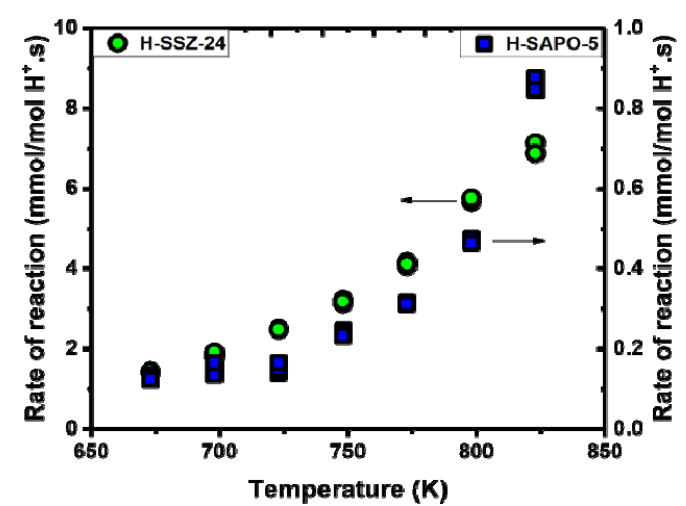

Fig. 3. Reaction rate versus temperature. Reaction conditions: $\mathrm{CT}_{\mathrm{H}-\mathrm{SAPO}-5}$ $=0.13 \mathrm{~s} \cdot \mathrm{mmol} \mathrm{H}^{+} \mathrm{cm}^{-3}, \mathrm{CT}_{\mathrm{H}-\mathrm{Ssz}-24}=0.013 \mathrm{~s} \cdot \mathrm{mmol} \mathrm{H}^{+} \mathrm{cm}^{-3}, P_{\text {ethene }}=33 \mathrm{kPa}$, ethene conversion $<1 \%$.

parent activation energy, it is substantially lower over H-SSZ-24 than over H-SAPO-5 (Fig. 3, Table 2). This observation is in line with previous studies of ethene oligomerization conducted at lower temperatures [15].

Next, the product selectivity obtained over the two catalysts at similar conversion is considered (Fig. 4). $n$-Butenes, propene and iso-butene were the main products ( $>95 \%$ selectivity), with only minor amounts of $\mathrm{C}_{5}-\mathrm{C}_{6}$ alkenes and saturated hydrocarbons, over both catalysts. No aromatic products were observed in the reactor effluent. Hence, we will refer to the oligomerisation-cracking mechanism when discussing the further findings of this study (Scheme 1). The $n$-butene selectivity was found to decrease with increasing conversion, while propene selectivity showed a corresponding increase with increasing conversion. Iso-butene selectivity varied only slightly with conversion over H-SAPO-5, but decreased with increasing conversion over H-SSZ-24. Overall, these results suggest that both n-butene and iso-butene are precursors to propene formation. Notably, propene selectivity was substantially higher over H-SSZ-24 than over H-SAPO-5 at similar conversion (e.g. $68 \%$ versus $36 \%$ at $0.5 \%$ conversion). With reference to Scheme 1, this observation suggests that cracking of $\mathrm{C}_{6}$ alkenes to form propene is more rapid over the stronger acid catalyst, H-SSZ-24. This conclusion is in line with prior literature, reporting that only strongly acidic zeolites could crack $\mathrm{C}_{5+}$ alkenes to ethene and propene, whereas less-acidic zeotypes favored oligomerization followed by cracking to higher alkenes [9,23]. Miyaji et al. [36] showed that 2-methyl-2-butene and 1-pentene were not cracked in a monomolecular mechanism over H-SAPO-5.

Considering the selectivity versus conversion plots in more detail, selectivity changes were dramatic at less than $0.2 \%$ conversion, and seemed to approach steady state already at $0.5 \%$ conversion. Hence, it is of interest to explore whether the observed selectivities are thermodynamically rather than kinetically controlled. The reaction quotient of each product with respect to the primary product ( $n$-butene) in the reactor effluent was calculated and compared with the equilibrium constant of the corresponding interconversion reaction. The results are shown in Fig. 5. 1-Butene, trans-2-butene and cis-2-butene were found to be in equilibrium under all conditions explored in this study (as exemplified by the data shown in Fig. 5(a)); demonstrating the rapid proton exchange reaction in alkenes over Brønsted acid catalysts. For this reason, 1- and 2-butenes are lumped together and presented as one product, $n$-butene, in all graphs presented in this contribution. On the other hand, neither the $n$-butene-isobutene reaction nor the $n$-butene-propene reaction was equilibrated in the reactor effluent at any of the test temperatures, and the $n$-butene-isobutene reaction quotient differed between H-SAPO-5 and H-SSZ-24 (Fig. 5b). Hence, the differences in proton affinity of the two catalysts, as well as of the primary, secondary and tertiary carbons involved in the oligomerization, cracking and $\mathrm{H}$ - and $\mathrm{CH}_{3}$-transfer reactions, induce a steady-state, rather than thermodynamic, product distribution when reacting ethene over the two catalysts. Furthermore, the steady-state selectivity to propene is strongly enhanced over the more acidic H-SSZ-24 catalyst compared to H-SAPO-5.

Table 2

Summary of apparent reaction order, apparent activation energy ( $\left.E a / \frac{\mathrm{kJ}}{\mathrm{mol}}\right)$, and apparent reaction $\mathrm{rate}\left(\mathrm{mmol} / \mathrm{mol} \mathrm{H}^{+} . \mathrm{s}\right)$, for ethene reaction.

\begin{tabular}{|c|c|c|c|c|c|c|c|c|}
\hline \multirow[b]{3}{*}{$T / K$} & \multicolumn{4}{|c|}{$H-S A P O-5$} & \multicolumn{4}{|c|}{$H-S S Z-24$} \\
\hline & \multicolumn{2}{|c|}{ Reaction order, app } & \multirow{2}{*}{$\begin{array}{l}E_{a, a p p} \pm 4 \\
698-823\end{array}$} & \multirow{2}{*}{$\begin{array}{c}\text { rate }_{\text {app }} \\
748\end{array}$} & \multicolumn{2}{|c|}{ Reaction order, app } & \multirow{2}{*}{$\frac{E_{a, a p p} \pm 3}{698-823}$} & \multirow{2}{*}{$\frac{\text { rate }_{\text {ap }}}{748}$} \\
\hline & 673 & 748 & & & 673 & 748 & & \\
\hline Overall & 2.0 & 2.1 & 80 & 0.33 & 1.5 & 1.9 & 52 & 6.5 \\
\hline $\mathrm{C}_{3} \mathrm{H}_{6}$ & 1.8 & 2.2 & 83 & 0.11 & 1.2 & 2.3 & 62 & 2.1 \\
\hline $\mathrm{i}-\mathrm{C}_{4} \mathrm{H}_{8}$ & 2.1 & 2.0 & 92 & 0.05 & 2.0 & 1.9 & 63 & 0.9 \\
\hline$n-C_{4} H_{8}$ & 2.0 & 2.1 & 64 & 0.15 & 1.7 & 1.7 & 43 & 3.5 \\
\hline
\end{tabular}



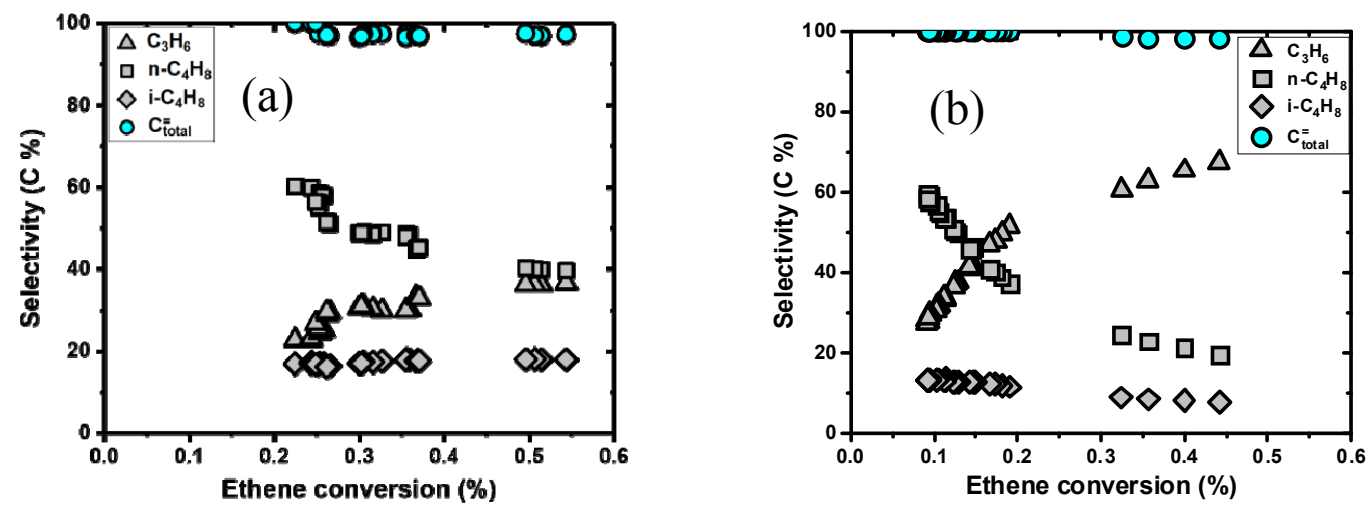

Fig. 4. Selectivity versus ethene conversion over. H-SAPO-5 (a), and H-SSZ-24 (b). Reaction conditions: $\mathrm{CT}_{\mathrm{H}-\mathrm{SAPO}-5}=0.22-0.57 \mathrm{~s} . \mathrm{mmol} \mathrm{H}^{+} \mathrm{cm}^{-3}$, $\mathrm{CT}_{\mathrm{H}-\mathrm{SSZ}-24}$ $=0.038 \mathrm{~s} . \mathrm{mmol} \mathrm{H}^{+} \mathrm{cm}^{-3}, P_{\text {ethene }}=33 \mathrm{kPa}, T=748 \mathrm{~K}, \mathrm{C}^{=}$total represents total selectivity to alkenes.

(a)

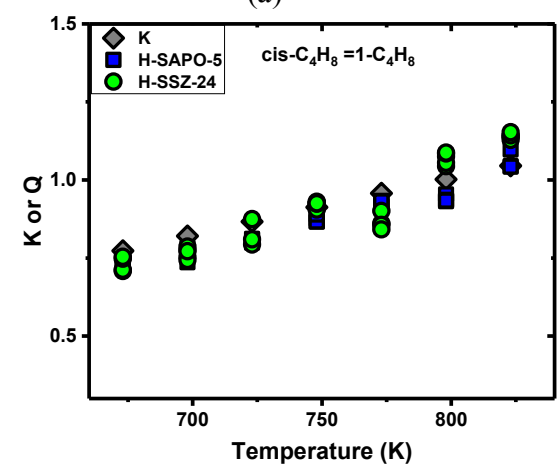

(b)

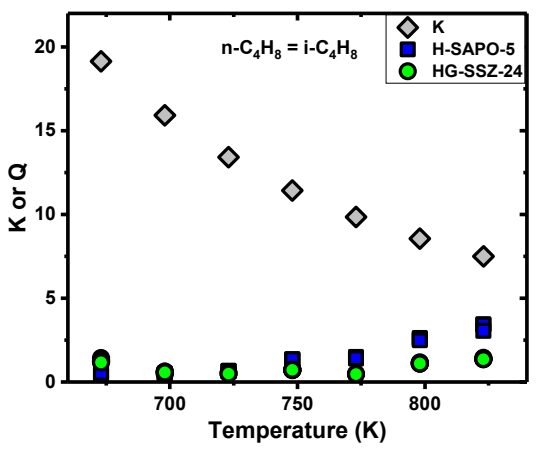

(c)

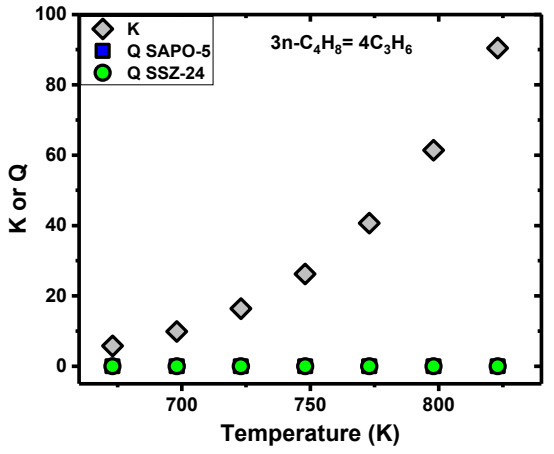

Fig. 5. K or Q values versus temperature, $\mathrm{Q}$ values were calculated based on molar yield of $\mathrm{Cn}$ from ethene reaction with conversions < $1 \%$.

\subsection{Cis-2-butene oligomerization}

Cis-2-butene conversion versus contact time graphs obtained over H-SAPO-5 and H-SSZ-24 at $748 \mathrm{~K}$ and $4.5 \mathrm{kPa}$ $n$-butene are shown in Fig. 6 . The graphs were linear at low conversions, but started to level off around 10\% conversion. Similar conversion of n-butene was obtained at one order of magnitude shorter contact time over H-SSZ-24 compared to H-SAPO-5 in the linear part of the graphs at (9\% vs. $4 \%$ con- version at 0.6 vs. $6\left(\mathrm{~s} . \mu \mathrm{mol} \mathrm{H} \mathrm{H}^{+}\right) / \mathrm{cm}^{3}$ contact time, respectively). Hence, the rate difference over the two catalysts was similar to that observed for an ethene feed in Section 3.2 (albeit at lower partial pressures; 4.5 versus $33 \mathrm{kPa}$ ) (Fig. 1).

Considering next product selectivity at $748 \mathrm{~K}$, isobutene was the main product over both catalysts, followed by pentene and propene (Fig. 7). The total selectivity to those three products was higher than $95 \%$ in the $0-5 \%$ conversion range over both catalysts. The remaining products were mainly saturated products, with traces of other alkenes. No aromatic products
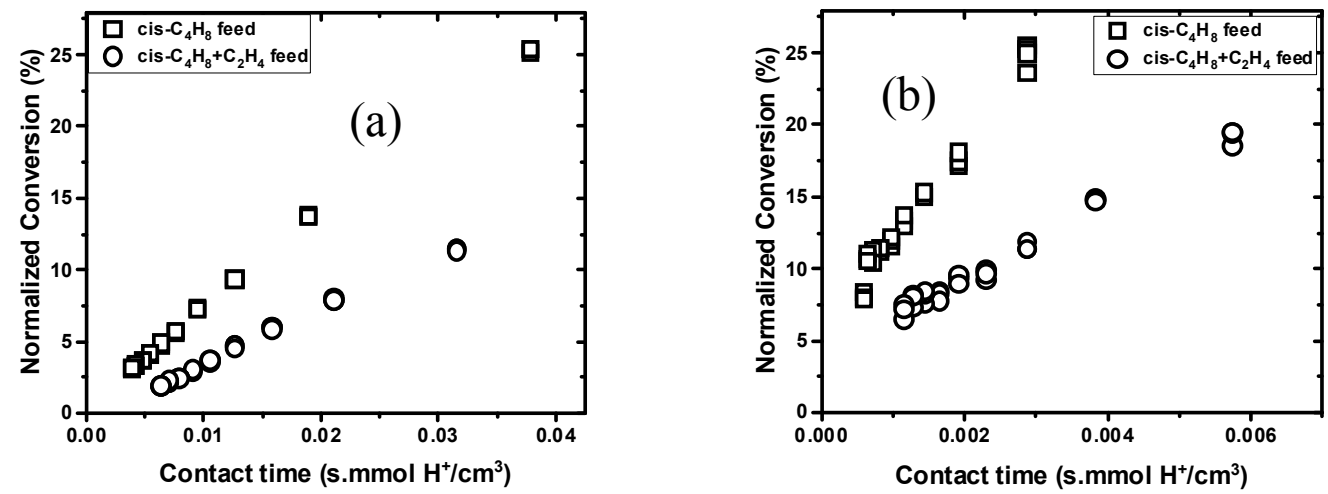

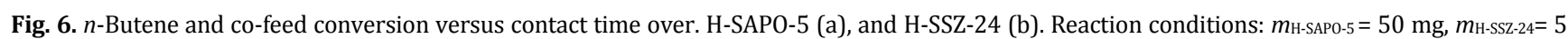
$\mathrm{mg}, P_{\text {cis-2-butene }}=4.5 \mathrm{kPa}, P_{\text {ethene }}=10 \mathrm{kPa}, T=748 \mathrm{~K}$. 

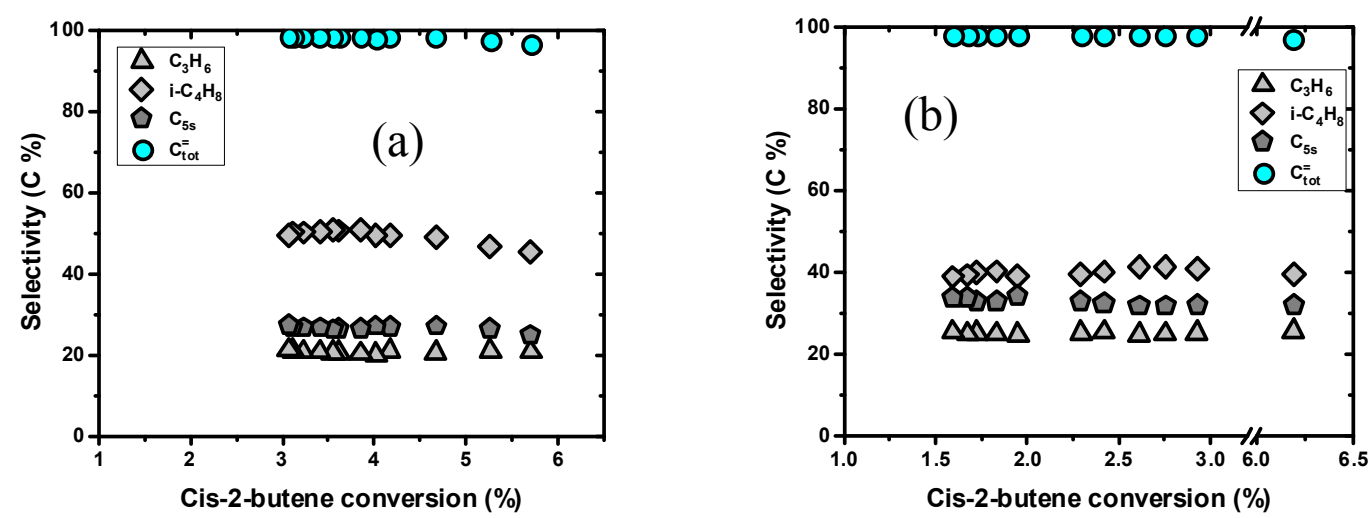

Fig. 7. Selectivity versus $n$-butene conversion over. (a) H-SAPO-5, and H-SSZ-24(b). Reaction conditions: $\mathrm{CT}_{\mathrm{H}-\mathrm{SAPO}-5}=3.8 \mathrm{~s}$. $\mu$ mol $\mathrm{H}^{+} / \mathrm{cm}^{3}$, CT $\mathrm{H}_{\mathrm{SSZ}-24}=$ $0.41 \mathrm{~s} . \mu \mathrm{mol} \mathrm{H}{ }^{+} / \mathrm{cm}^{3}, P_{\text {cis-2-butene }}=4.5 \mathrm{kPa}, T=748 \mathrm{~K}, \mathrm{C}=$ total represents total selectivity to alkenes.

were detected in the reactor effluent.

Butene dimerisation yields $\mathrm{C}_{8}=$ that may undergo hydride and methyl shifts and crack to form either pentene and propene, or isobutene. Additional isobutene may be formed by a monomolecular mechanism (Scheme 1). This simplified mechanism would yield pentene:propene in a 1:1 molar ratio, the equivalent of a 5:3 carbon selectivity ratio (as presented in Fig. 7). Close inspection of the data in Fig. 7 shows that the selectivity trends with increasing conversion is similar for the two products, but that the propene vs. pentene selectivity is higher than expected from $\mathrm{C}_{8}=$ cracking over both catalysts. This result indicates that the products are formed via a more complex mechanism of parallel and sequential reactions.

Some selectivity differences were observed over the two catalysts. In particular, the iso-butene selectivity was higher over H-SAPO-5 than over H-SSZ-24. However, product selectivity changed slowly with conversion and approached similar values at the highest measured conversion, $5.5 \%$, where the isobutene:pentene:propene selectivity was 44:28:22 over H-SAPO-5 and 40:30:27 over H-SSZ-24 (Fig. 7).

Reaction orders and apparent activation energies for the overall reaction and main products formation are shown in Figs. 8-11 and Table 3. The apparent reaction order was similar for $n$-butene conversion over the two catalysts at $673-748 \mathrm{~K}$

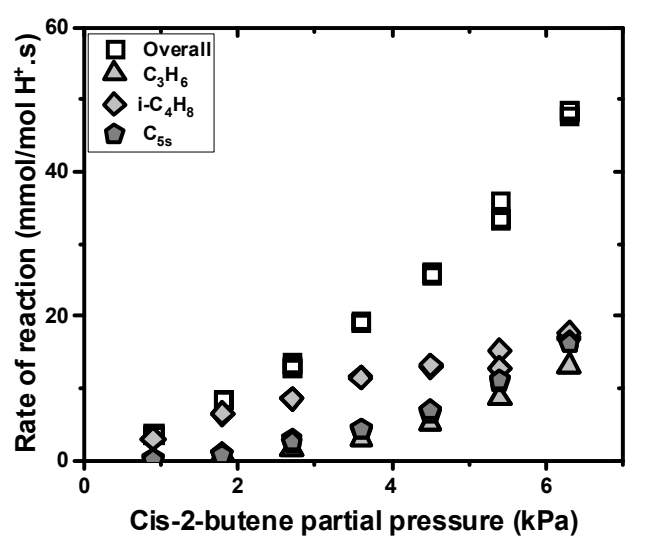

Fig. 8. Reaction rate versus n-butene pressure over H-SAPO-5. Reaction conditions: $\mathrm{CT}=3.8 \mathrm{~s} . \mu \mathrm{mol} \mathrm{H} \mathrm{H}^{+} / \mathrm{cm}^{3}, T=748 \mathrm{~K}$, conversion $<10 \%$.
(1.3 vs. 1.4 and 1.5 vs. 1.6 over H-SAPO-5 and H-SSZ- 24 at 673 and $748 \mathrm{~K}$, respectively; Figs. 8 and 9; Table 3). At $823 \mathrm{~K}$, however, there was a substantial decrease in the overall reaction order for both catalysts (0.9 vs. 1.3 over H-SAPO-5 and H-SSZ-24, respectively), suggesting a shift in the dominant reaction path with increasing temperature. Further support for such a shift was found from plots of reaction rates versus temperature. The rate of product formation showed two regimes

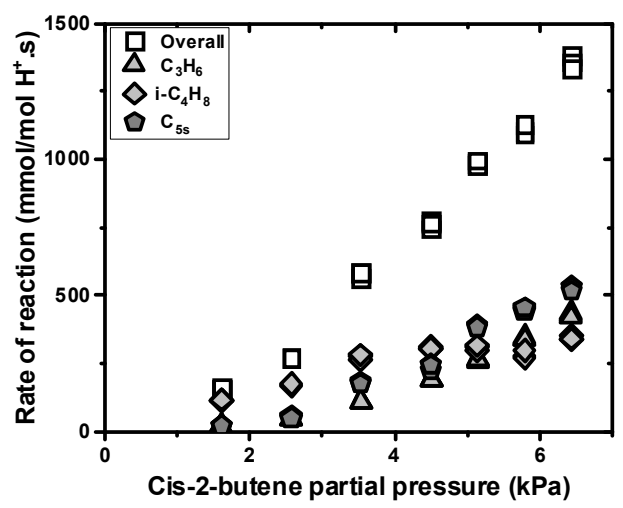

Fig. 9. Reaction rate versus n-butene pressure over H-SSZ-24. Reaction conditions: $\mathrm{CT}=0.57 \mathrm{~s}$. $\mu \mathrm{mol} \mathrm{H} \mathrm{H}^{+} / \mathrm{cm}^{3}, T=748 \mathrm{~K}$, conversion $<10 \%$.

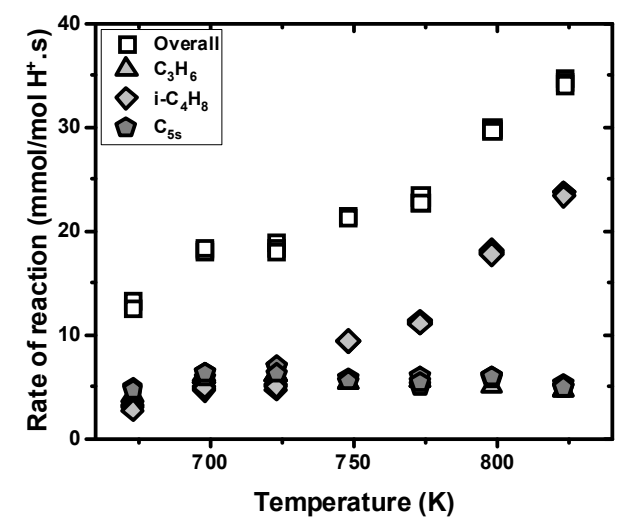

Fig. 10. Reaction rate versus temperature for $n$-butene reaction over H-SAPO-5. Reaction conditions: CT $=3.8 \mathrm{~s} . \mu \mathrm{mol} \mathrm{H} \mathrm{H}^{+} / \mathrm{cm}^{3}, P_{\text {cis-2-butene }}=4.5$ $\mathrm{kPa}$, conversion $<10 \%$. 


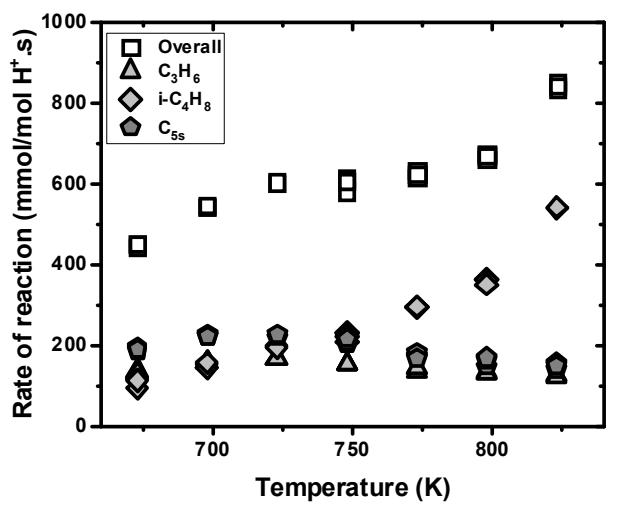

Fig. 11. Reaction rate versus temperature for $n$-butene reaction over H-SSZ-24. Reaction conditions: $\mathrm{CT}=0.41 \mathrm{~s} . \mu \mathrm{mol} \mathrm{H} \mathrm{H}^{+} / \mathrm{cm}^{3}, P_{\text {cis-2-butene }}=4.5$ $\mathrm{kPa}$, conversion $<10 \%$.

within the studied temperature range (673-723 $\mathrm{K}$ and 748-823 K) over both catalysts (Figs. 10 and 11), with an increase in the apparent activation energy $\left(\mathrm{E}_{\mathrm{a}, \mathrm{app}}\right)$ of $n$-butene conversion with increasing temperature, from 26 to $42 \mathrm{~kJ} / \mathrm{mol}$ over H-SAPO-5 and from 21 to $28 \mathrm{~kJ} / \mathrm{mol}$ over H-SSZ-24 (Table $3)$. When considering individual reaction products, however, the $E_{\mathrm{a}, \mathrm{app}}$ of formation increased with increasing temperature for iso-butene, but turned negative with increasing temperature for propene and pentene, over both catalysts (Figs. 10 and 11, Table 3). Furthermore, reaction orders for the formation of individual products were close to 2 for propene and pentene, but lower than 1 for isobutene, at 748 and $823 \mathrm{~K}$ (Table 3). Overall, the results obtained indicate that isobutene is mainly formed via a monomolecular mechanism in this temperature range, while propene and pentene are formed from butene oligomers and subsequent methyl shift/cracking/oligomerization reactions.

Thermodynamic calculations of $n$-butene conversion to either iso-butene or propene-pentene showed that product formation was far below equilibrium under the conditions studied (Fig. S4). Furthermore, the interconversion of iso-butene to propene-pentene favoured propene-pentene at the lower temperatures, and isobutene at the highest temperatures, compared to thermodynamic equilibrium (Fig. 12(a)). These data suggest that product distribution did not reach equilibrium under the conditions studied. However, the apparent negative activation energy of propene and pentene formation in the upper temperature regime strongly suggests that their formation was limited by the decreasing equilibrium constant of formation of butene oligomers with increasing temperatures
(Fig. 12(b)). The strong thermodynamic influence on product distribution impedes a detailed kinetic analysis of the data obtained. However, it is interesting to observe that a high selectivity to iso-butene was obtained at the higher temperatures (> $60 \%$ over both catalysts).

\subsection{Ethene and cis-2-butene co-feed reaction}

Finally, we consider the reaction of cis-2-butene co-fed with ethene over the two catalysts. Conversion versus contact time plots at $748 \mathrm{~K}$, with $4.5 \mathrm{kPa}$ cis-2-butene and $10 \mathrm{kPa}$ ethene feed, are shown in Fig. 6, together with data for the pure cis-2-butene feed. At any given contact time, the co-feed conversion was lower than pure cis-butene conversion over both catalysts. This result is reasonable since both $n$-butene and ethene are considered reactants in conversion calculations. At similar contact times, the feed conversion was more than an order of magnitude higher over H-SSZ-24 than H-SAPO- 5 for the co-feed reaction, as observed for the pure cis-2-butene reaction (Fig. 6).

Considering next the products of the co-feed tests (Figs. 13 and S5), the main products were the same as those observed in pure cis-butene reaction, i.e.; isobutene, propene and pentene. However, the propene to pentene ratio was higher for the co-feed than for the pure butene feed over both catalysts (Fig. 7 and S5 versus Fig. 13). Furthermore, a clear decrease in iso-butene selectivity, with a corresponding increase in propene selectivity, was observed with increasing conversion (0-5\% conversion range) in the co-feed experiments over both catalysts; clearly indicating that isobutene reacts with ethene to form hexene as an intermediate to propene formation.

\section{Concluding discussion and outlook}

The aim of this study was to elucidate whether ethene oligomerisation, and in particular, product selectivity, would be influenced by the Brønsted acid strength of zeolite/zeotype catalysts, under conditions that favour $\mathrm{C}_{3}-\mathrm{C}_{5}$ product formation (673-823 K). Care was taken to perform the study under differential conditions, while at the same time obtaining results that represent low, medium and high ethene conversion. To this end, three feed compositions were studied: (1) A pure ethene feed, that corresponds to the entrance of a fixed bed flow reactor; (2) an ethene $-n$-butene co-feed, with an ethene:n-butene ratio that mimics $26 \%$ ethene conversion to the primary product, butene; and (3) a pure $n$-butene feed that mimics the situation of full ethene conversion to the primary

Table 3

Summary of apparent reaction order, apparent activation energy $\left(\mathrm{Ea} / \frac{\mathrm{kJ}}{\mathrm{mol}}\right)$, and apparent reaction rate $\left(\mathrm{mmol} / \mathrm{mol} \mathrm{H}^{+} . \mathrm{s}\right)$, for $n$-butene reaction.

\begin{tabular}{|c|c|c|c|c|c|c|c|c|c|c|c|c|}
\hline \multirow[b]{3}{*}{$T / K$} & \multicolumn{6}{|c|}{ H-SAPO-5 } & \multicolumn{6}{|c|}{ H-SSZ-24 } \\
\hline & \multicolumn{3}{|c|}{ Reaction order, app } & \multirow{2}{*}{$\begin{array}{l}E_{a, a p p} \mathbf{\pm 4} \\
673-723\end{array}$} & \multirow{2}{*}{$\begin{array}{c}\boldsymbol{E a} \pm \mathbf{7} \\
748-823\end{array}$} & \multirow{2}{*}{\begin{tabular}{|c|} 
rate $_{\text {app }}$ \\
748
\end{tabular}} & \multicolumn{3}{|c|}{ Reaction order, app $_{\text {, }}$} & \multirow{2}{*}{$\begin{array}{l}\boldsymbol{E} \boldsymbol{a}_{\text {, } \boldsymbol{~} p \boldsymbol{\pm} \mathbf{\mathbf { 3 }}} \\
673-723\end{array}$} & \multirow{2}{*}{$\begin{array}{l}\boldsymbol{E}_{a, a p p} \pm \mathbf{5} \\
748-823\end{array}$} & \multirow{2}{*}{$\begin{array}{c}\text { rate }_{\text {app }} \\
748\end{array}$} \\
\hline & 673 & 748 & 823 & & & & 673 & 748 & 83 & & & \\
\hline Over all & 1.3 & 1.5 & 0.9 & 26 & 42 & 26 & 1.4 & 1.6 & 1.3 & 21 & 28 & 770 \\
\hline $\mathrm{C}_{3} \mathrm{H}_{6}$ & 1.5 & 2.3 & 2.2 & 32 & -17 & 5 & 1.7 & 2.4 & 2.3 & 15 & -8 & 190 \\
\hline $\mathrm{C}_{5} \mathrm{H}_{10}$ & 1.4 & 2.2 & 1.9 & 24 & -11 & 7 & 2.2 & 2.3 & 2.2 & 11 & -18 & 240 \\
\hline$i-C_{4} H_{8}$ & - & 0.8 & 0.6 & 42 & 83 & 13 & - & 0.6 & 0.5 & 46 & 62 & 310 \\
\hline
\end{tabular}



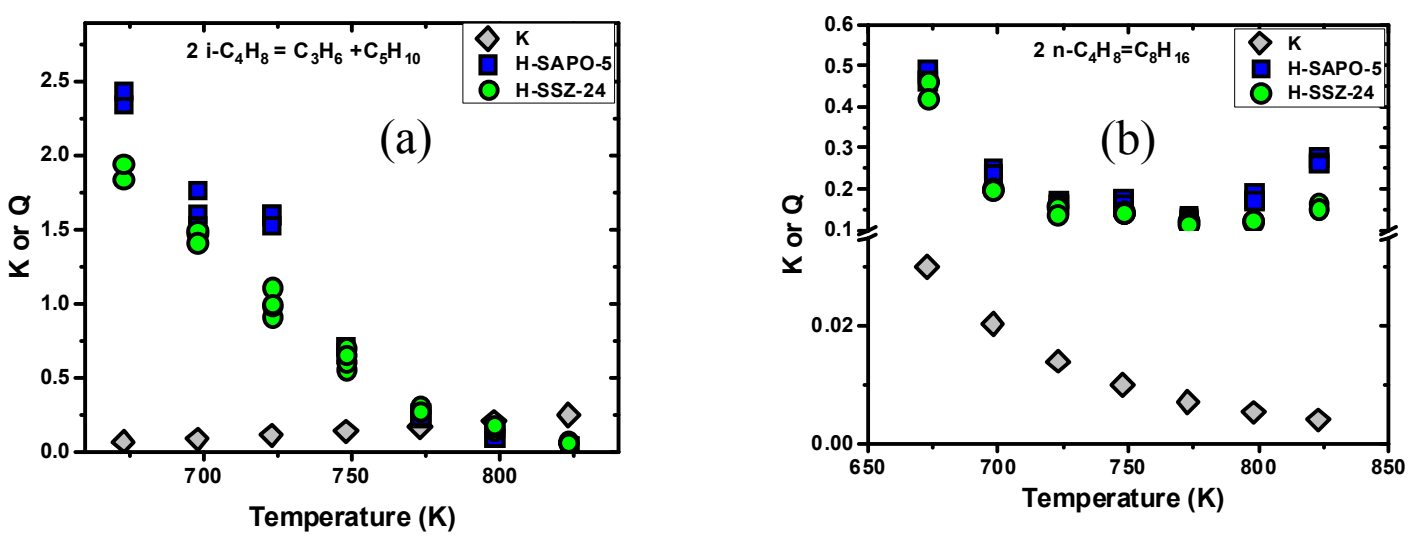

Fig. 12. K or $Q$ values versus temperature, $Q$ values were calculated based on molar yield of $\mathrm{Cn}$ from $n$-butene reaction with conversions $<10 \%$.
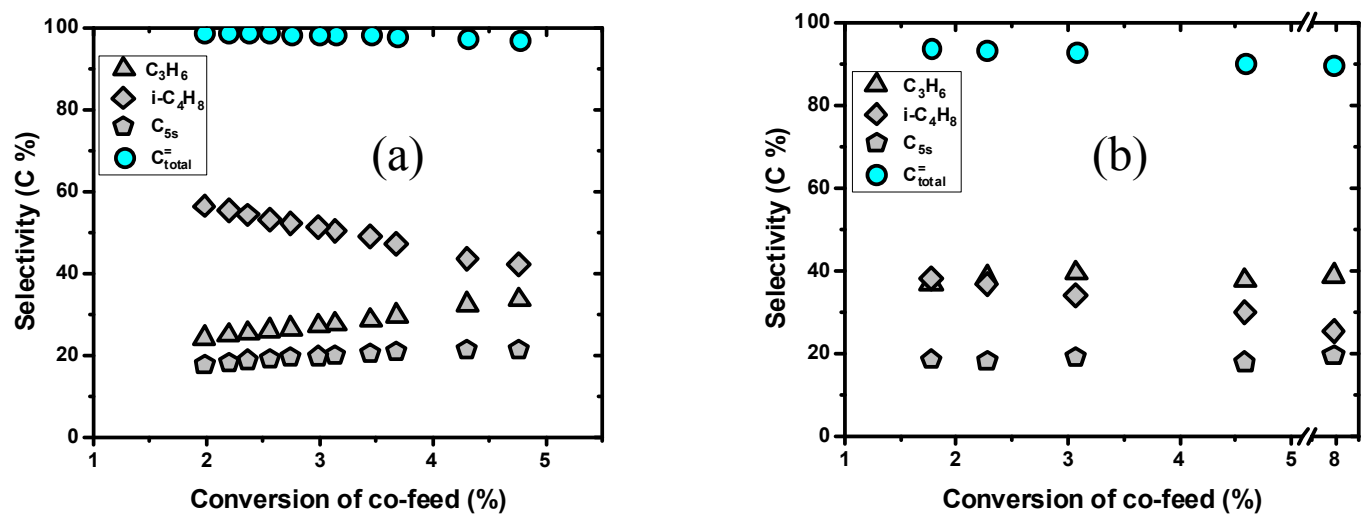

Fig. 13. Selectivity versus co-feed conversion over. $\mathrm{H}-\mathrm{SAPO}-5$ (a), and H-SSZ-24 (b). Reaction conditions: $\mathrm{CT}_{\mathrm{H}-\mathrm{SAPO}-5}=15.1 \mathrm{~s} . \mu \mathrm{mol} \mathrm{H}^{+} / \mathrm{cm}^{3}$, $\mathrm{CT}_{\mathrm{H}-\mathrm{SSZ}-24}=$ $2.23 \mathrm{~s} . \mu \mathrm{mol} \mathrm{H}+\mathrm{cm}^{3}, P_{\text {cis-2-butene }}=3.6 \mathrm{kPa}, P_{\text {ethene }}=20 \mathrm{kPa}, T=748 \mathrm{~K}, \mathrm{C}={ }_{\text {total }}$ represents total selectivity to alkenes.

product, butene, when approaching the reactor exit.

In the first part of the study, where ethene was fed alone over the two catalysts, it was observed that the ethene conversion rate was more than an order of magnitude higher over the more acidic H-SSZ-24 than over H-SAPO-5 at $748 \mathrm{~K}$ (Figs. 1 and 2 ). Furthermore, the reaction order in ethene was high over both catalysts, but highest over H-SAPO-5, indicating low surface coverage in ethene over both catalysts. Finally, the apparent activation energy of ethene oligomerization was substantially lower over the more acidic H-SSZ-24 catalyst. According to the Hammond postulate [37], the transition state of an exothermic reaction is closer to the reactants, i.e.; the sorbed ethene molecules, than the products. In line with our results, Iglesia and co-workers recently reported combined experimental and computational studies of propene oligomerization over Brønsted-acidic catalysts at lower temperatures and demonstrated a correlation between stabilisation of the bulky, C-C forming transition state and catalyst acid strength, leading to higher turn-over rates over the more acidic catalyst [16].

Considering next product selectivity at $0-1 \%$ ethene conversion, there are clear differences between the two catalysts: Both catalysts yielded $n$-butene and iso-butene even at the lowest conversion, with an initial iso-butene selectivity close to 15\% (Fig. 4). However, the more acidic H-SSZ-24 catalyst converted $n$ - and iso-butene more rapidly with ethene to form propene (via hexene) as the main product at ethene conversions $>0.2 \%$. Over H-SAPO-5, $n$-butene and in particular iso-butene conversion was slower, and propene selectivity barely surpassed $n$-butene selectivity at the highest measured conversion $(0.5 \%)$. Furthermore, the $n$-butene: iso-butene ratio decreased from 3 to 2 over the measured conversion range.

The 2 orders of magnitude higher rate of $n$-butene conversion compared to ethene conversion over both catalysts at this temperature, in spite of a much lower $n$-butene partial pressure, as well as the asymptotic conversion-selectivity curve shape, strongly suggests that the observed selectivity difference relates to a pool of parallel and sequential reactions, rather than pristine reaction rate differences.

In order to rationalise these selectivity differences, it is necessary to take a closer look at the mechanism of oligomerisation, methyl shift and cracking reactions, respectively. An enlarged version of the oligomerisation-cracking route in Scheme 1 , including protonated intermediates, is shown in Scheme 2. It is clear from Scheme 2 that in order to form cracking products that differ from the reactants, the cracking reaction needs to be preceded by one or several $(2,3)$ methyl shifts. The low apparent reaction order in $n$-butene observed for isobutene formation from a cis-2-butene feed $(0.8$ and 0.6 over H-SAPO-5 and H-SSZ-24, respectively, at $748 \mathrm{~K}$; Table 2) suggests that it is primarily formed via the monomolecular route, i.e.; a methyl 


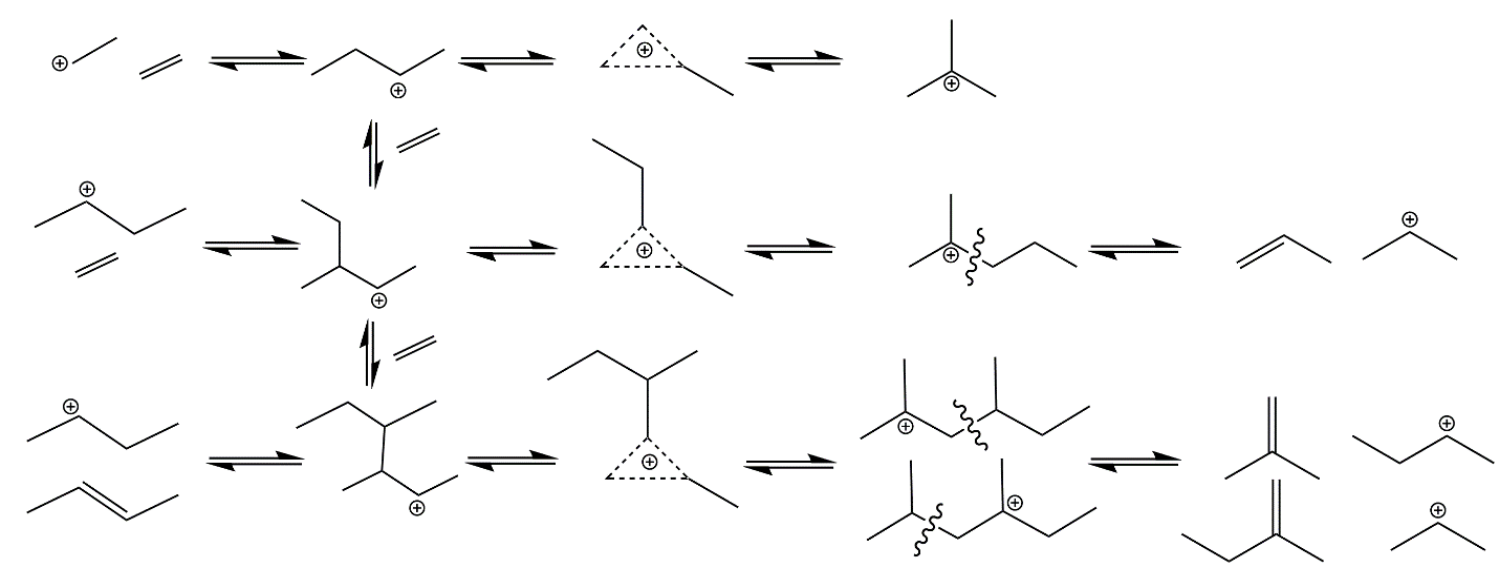

Scheme 2. An extended oligomerization mechanisms showing isomerization via methyl shift-cracking.

shift within the butyl/butoxy intermediate at this temperature. The higher selectivity towards iso-butene, compared to propene and pentene, over H-SAPO-5 versus H-SSZ-24 for all feeds studied in this contribution, further suggests that the methyl shift reaction is less influenced by acid strength than the oligomerisation and cracking reactions, likely because the transition from a secondary to a tertiary carbocation is energetically favoured [38,39].

In this context, it is interesting to note that the extrapolated isobutene selectivity at zero conversion, i.e.; the possibly primary isobutene selectivity over H-SSZ-24 and H-SAPO-5, respectively, is very similar. This observation could suggest that the relative rates of ethene oligomerization and an immediate methyl shift that converts $n$-butyl to isobutyl before product desorption, are either very similar over the two catalysts, or the interconversion reaction is so rapid that a steady-state between the $n$-butyl and isobutyl intermediates is established before deprotonation to form either $n$-butene or isobutene. The relative ethene oligomerisation and $\mathrm{C}_{6}$ cracking rates, however, are much slower over the less acidic catalyst, because this reaction implies the formation of a small, primary carbocation intermediate (Scheme 2). The importance of acid strength in $\mathrm{C}_{5}$ and $\mathrm{C}_{6}$ alkene cracking reactions has been demonstrated in previous studies $[15,36]$. For higher intermediates, the relative rate differences over the two catalysts vanishes, leading to more similar product distribution over the two catalysts (Fig. 7).

Finally, the apparent negative activation energy of propene and pentene formation in the upper temperature regime when feeding cis-2-butene over both catalysts, strongly suggests that their formation was limited by the decreasing equilibrium constant of formation of butene oligomers with increasing temperatures (Fig. 12) and that the life-time of the dimer was not sufficient to enable the methyl shift required for subsequent propene, pentene and iso-butene formation to an appreciable extent $[33,40]$. At the highest temperature $(823 \mathrm{~K})$, both catalysts showed high and similar selectivity to iso-butene $(68 \%$ and $71 \%$, respectively over H-SAPO-5 and H-SSZ-24).

Returning to the characterisation data for the two catalysts (Table 1), the more acidic H-SSZ-24 possessed smaller crystal size than H-SAPO-5. This difference could lead to a higher effi- ciency factor, hence higher conversion, and lower abundance of secondary reactions for the more acidic catalyst. We are not in position to assess the efficiency factor of the two catalysts. However, the selectivity to consecutive products was substantially higher over the more acidic catalyst, suggesting that the crystal size was not the dominant factor for the activity and selectivity differences observed between the two catalysts.

Overall, the results obtained in this contribution showed that the catalyst with higher acid strength, H-SSZ-24, led to substantially higher ethene conversion rate and favoured propene formation from ethene, compared to H-SAPO-5, at low ethene conversion. However, the selectivity difference decreased under conditions that mimicked increasing ethene conversion, and the product distribution was similar over the two catalysts under conditions mimicking full ethene conversion.

\section{References}

[1] J. C. Mol, J. Mol. Catal. A, 2004, 213, 39-45.

[2] J. A. Moulijn, M. Makkee, A. V. Diepen, 2nd ed., Chemical Process Technology, John Wiley \& Sons, 2013, 7-122.

[3] V. Hulea, ACS Catal., 2018, 8, 3263-3279.

[4] M. Iwamoto, Molecules, 2011, 16, 7844-7863.

[5] R. Henry, M. Komurcu, Y. Ganjkhanlou, R. Y. Brogaard, L. Lu, K.-J. Jens, G. Berlier, U. Olsbye, Catal. Today, 2018, 299, 154-163.

[6] H. Oikawa, Y. Shibata, K. Inazu, Y. Iwase, K. Murai, S. Hyodo, G. Kobayashi, T. Baba, Appl. Catal. A, 2006, 312, 181-185.

[7] G. Spoto, S. Bordiga, G. Ricchiardi, D. Scarano, A. Zecchina, E. Borello, J. Chem. Soc., Faraday Transactions, 1994, 90, 2827-2835.

[8] B. Lin, Q. Zhang, Y. Wang, Ind. Eng. Chem. Res., 2009, 48, 10788-10795.

[9] L. Lin, C. Qiu, Z. Zhuo, D. Zhang, S. Zhao, H. Wu, Y. Liu, M. He, J. Catal., 2014, 309, 136-145.

[10] V. Blay, E. Epelde, R. Miravalles, L. A. Perea, Catal. Rev. Sci. Eng., 2018, 60, 278-335.

[11] E. V. Anslyn, D. A. Dougherty, Modern Physical Organic Chemistry, University Science Books, 2006, 355-382.

[12] H. Zhou, Y. Wang, F. Wei, D. Wang, Z. Wang, Appl. Catal. A, 2008, 348, 135-141.

[13] S. A. Tabak, F. J. Krambeck, W. E. Garwood, AICHE J., 1986, 32, 1526-1531. 


\title{
Graphical Abstract
}

Chin. J. Catal., 2019, 40: 1766-1777 doi: S1872-2067(19)63426-1

Ethene and butene oligomerization over isostructural H-SAPO-5 and H-SSZ-24: Kinetics and mechanism

Christian Ahoba-Sam, Marius Westgård Erichsen, Unni Olsbye * University of Oslo, Norway

Reactor with three zones; representing the three measurement regimes. On the side; three typical conversion - selectivity graphs for H-SAPO-5 and H-SSZ-24, representing C3-C5 alkene selectivity in the three regimes.

[14] W. E. Garwood, ACS Symp. Series, 1983, 218, 383-396.

[15] M. L. Sarazen, E. Doskocil, E. Iglesia, ACS Catal., 2016, 6, 7059-7070.

[16] M. L. Sarazen, E. Doskocil, E. Iglesia, J. Catal., 2016, 344, 553-569.

[17] M. L. Sarazen, E. Iglesia, Proc. Natl. Acad. Sci. USA, 2017, 114, E3900-E3908.

[18] W. Dai, X. Sun, B. Tang, G. Wu, L. Li, N. Guan, M. Hunger, J. Catal., 2014, 314, 10-20.

[19] H. H. Mooiweer, K. P. de Jong, B. Kraushaar-Czarnetzki, W. H. J. Stork, B. C. H. Krutzen, Stud. Surf. Sci. Catal., 1994, 84, 2327-2334.

[20] M. Guisnet, P. Andy, N. S. Gnep, C. Travers, E. Benazzi, J. Chem. Soc., Chem. Commun., 1995, 1685-1686.

[21] M. Guisnet, P. Andy, N. S. Gnep, E. Benazzi, C. Travers, J. Catal., 1996, 158, 551-560.

[22] J. Houžvička, V. Ponec, Catal. Rev. Sci. Eng., 1997, 39, 319-344.

[23] L. F. Lin, S. F. Zhao, D. W. Zhang, H. Fan, Y. M. Liu, M. Y. He, ACS Catal., 2015, 5, 4048-4059.

[24] J. Houžvička, O. Diefenbach, V. Ponec, J. Catal., 1996, 164, 288-300.

[25] P. Meriaudeau, R. Bacaud, L. N. Hung, A. T. Vu, J. Mol. Catal. A, 1996, 110, L177-L179.

[26] J. Čejka, B. Wichterlová, P. Sarv, Appl. Catal. A, 1999, 179, 217-222.

[27] G. Seo, M. Y. Kim, J. H. Kim, Catal. Lett., 2000, 67, 207-213.
[28] J. Houžvička, S. Hansildaar, V. Ponec, J. Catal., 1997, 167, 273-278.

[29] M. Westgård Erichsen, S. Svelle, U. Olsbye, Catal. Today, 2013, 215, 216-223.

[30] M. Westgård Erichsen, S. Svelle, U. Olsbye, J. Catal., 2013, 298, 94-101.

[31] B. de Ménorval, P. Ayrault, N. S. Gnep, M. Guisnet, Appl. Catal. A, 2006, 304, 1-13.

[32] NIST, Thermodynamics Research Center, Standard Reference Database 85, Version 1.5 software, 2001.

[33] J. E. Kilpatrick, E. J. Prosen, K. S. Pitzer, F. D. Rossini, J. Res. Natl. Bureau Stand., 1946, 36, 559-612.

[34] A. N. Mlinar, P. M. Zimmerman, F. E. Celik, M. Head-Gordon, A. T. Bell, J. Catal., 2012, 288, 65-73.

[35] M. A. Makarova, K. M. Al-Ghefaili, J. Dwyer, J. Chem. Soc., Faraday Trans., 1994, 90, 383-386.

[36] A. Miyaji, Y. Sakamoto, Y. Iwase, T. Yashima, R. Koide, K. Motokura, T. Baba, J. Catal., 2013, 302, 101-114.

[37] G. S. Hammond, J. Am. Chem. Soc., 1955, 77, 334-338.

[38] P. Cnudde, K. De Wispelaere, L. Vanduyfhuys, R. Demuynck, J. Van der Mynsbrugge, M. Waroquier, V. Van Speybroeck, ACS Catal., 2018, 8, 9579-9595.

[39] M. Höchtl, A. Jentys, H. Vinek, Appl. Catal. A, 2001, 207, 397-405.

[40] B. A. De Moor, M.-F. Reyniers, O. C. Gobin, J. A. Lercher, G. B. Marin, J. Phys. Chem. C, 2010, 115, 1204-1219.

\section{同型H-SAPO-5和H-SSZ-24上的乙烯和丁烯齐聚反应：动力学和机理}

\author{
Christian Ahoba-Sam, Marius Westgård Erichsen, Unni Olsbye * \\ 奥斯陆大学化学系, 材料科学和纳米技术中心, $\mathrm{N}-0315$ 奥斯陆, 挪威
}

摘要: B酸型分子笁和分子篮型材料是乙烯转化为高级烯烃的潜在催化剂. 本文在C3-C5 烯烃形成热力学优于高碳氢化合
物的条件下 $(673-823 \mathrm{~K}, 1 \mathrm{~atm})$, 研究了两种具有AFI结构但酸强度不同的H-SAPO-5 和H-SSZ-24催化剂上乙烯、顺式-2-丁
烯和乙烯-丁烯混合物的转化反应. 乙烯和顺式-2-丁烯分压分别在 $9-60$ 和 $0.9-8.1 \mathrm{kpa}$ 范围内变化, 接触时间分别在
$3.78-756$ 和 $0.573-76.4 \mathrm{~s} . \mu \mathrm{mol} \mathrm{H}^{+} / \mathrm{cm}^{3}$ 范围内变化. 在用于计算速率常数的条件范围内, 乙烯转化率小于 $1 \%$, 丁烯转化率小
于 $10 \%$. 在酸性较强的H-SSZ-24上乙烯转化率比H-SAPO- 5 高一个数量级 $(748 \mathrm{~K}$ 时为 6.5 对 $0.3 \mathrm{mmol} / \mathrm{mol} \mathrm{H}+. \mathrm{S}$, 戊烯 $=33$ 
$\mathrm{KPa})$, 乙烯中相应的反应级数较低(673 K时为 1.5 对 2.0$)$, 表观活化能较低(698-823 K时 52 对 $80 \mathrm{~kJ} / \mathrm{mol}$ ). 两种催化剂上顺式 -2-丁烯转化率以及乙烯和顺式-2-丁烯共进料的表观反应速率存在相似的差异. 然而, 顺式-2-丁烯转化为C3-C5烯烃受热 力学限制的影响很大, 妨碍了详细的动力学分析, 并导致在最高温度下主要生成异丁烯.

关键词: 乙烯齐聚; 丁烯齐聚; 动力学; 分子笁; 酸强度; H-SAPO-5; H-SSZ-24

收稿日期: 2019-06-17. 接受日期: 2019-06-20. 出版日期: 2019-11-05.

*通讯联系人. 电话: +4722855456 ; 电子信箱: unni.olsbye@kjemi.uio.no

本文的电子版全文由Elsevier出版社在ScienceDirect上出版(http://www.sciencedirect.com/science/journal/18722067). 